\title{
ACESSO À JUSTIÇA, MEDIAÇÃO JUDICIAL E FOMENTO À DESINVISIBILIZAÇÃO SOCIAL
}

\author{
Paula Camila Veiga Ferreira ${ }^{1}$
}

Roberto Henrique Pôrto Nogueira²

\begin{abstract}
Resumo. O ensaio pretende investigar o potencial da mediação na promoção do acesso à justiça, haja vista a sua configuração como mecanismo hábil a engendrar desinvisibilização social. Parte-se de reflexões sobre a teoria do pensamento pós-abissal, rumo à análise da natureza da mediação como ferramenta contra hegemônica. Parece viável, então, definir sua contribuição para a desinvisibilização dos mediados, considerando uma perspectiva ampla de justiça. A relevância da pesquisa é atribuída ao risco da distorção da mediação no âmbito da implementação judicial, de modo que os achados podem sugerir possibilidades comunicativas e colaborativas para a sua aplicação procedimental.
\end{abstract}

Palavras-chave. Acesso à Justiça; Mediação; Pluralismo Epistemológico; Pensamento PósAbissal; Desenvolvimento.

\section{ACCESS TO JUSTICE, JUDICIAL MEDIATION AND THE PROMOTION OF SOCIAL EMANCIPATION}

\begin{abstract}
The essay intends to investigate the potential of mediation in the promotion of access to justice, given its configuration as a mechanism to engender social emancipation. It starts with reflections on the post-abyssal thinking theory, towards the analysis of mediation as an antihegemonic tool. It seems feasible, then, to define its contribution to the emancipation of the people involved, considering a broad perspective of justice. The relevance of the research is related to the risk of the distortion of mediation during its judicial implementation, in a way
\end{abstract}

\footnotetext{
1 Mestranda em Novos Sujeitos, Novos Direitos pela UFOP. Especialista em Direito do Trabalho pela Universidade Cândido Mendes. E-mail: <paulaveiga.advogada@gmail.com>. Endereço profissional: Universidade Federal de Ouro Preto, Departamento de Direito - DEDIR. Campus Universitário s/nº Morro do Cruzeiro - 35400-000 - Ouro Preto, MG - Brasil. Telefone: (31) 35591545.

${ }^{2}$ Doutor e Mestre em Direito Privado pela PUC Minas. Especialista em Direito Tributário pela Faculdade de Direito Milton Campos. Professor Adjunto do Curso de Graduação e Mestrado Acadêmico em Direito da UFOP. E-mail: <portonogueira@gmail.com>. Endereço profissional: Universidade Federal de Ouro Preto, Departamento de Direito - DEDIR. Campus Universitário s/nº, Morro do Cruzeiro - 35400-000 - Ouro Preto, MG - Brasil. Telefone: (31) 35591545. Parte desse trabalho conta com o apoio do auxílio Pesquisador UFOP (DEDIR) 2017.
} 
that the findings may suggest communicative and collaborative possibilities for its procedural application.

Keywords. Access to justice; Mediation; Epistemological Pluralism; Post-Abyssal Thinking Theory; Development.

\section{INTRODUÇÃO}

O pensamento abissal, enquanto linha divisória de segregação e opressão, evidencia perspectivas diversas de ocultação, que restringem conteúdos híbridos (materiais, formais, sociais) de direitos e de exercício de direitos, e comboiam com a ausência de condições substanciais para a efetivação de liberdades, o que alicerça o aprisionamento de identidades e a firmação de barreiras de exclusão humana no que toca a processos de reconhecimento e emancipação, na medida em que perpetuam invisibilidades cunhadas por séculos de modernidade.

Os caminhos possíveis e a definição do protagonismo para esboçar fontes, significados, estruturas, processos e funções de estratégias de realização de justiça podem, desse modo, representar todo um espectro de pensamento, entre o abissal e o pós-abissal.

O trabalho visa a investigar o potencial, em abstrato, da mediação, para a promoção do acesso à justiça, mediante a aferição de sua possível qualidade de mecanismo hábil a engendrar a desinvisibilização social, por meio de reflexões sobre a teoria do pensamento pós-abissal.

Nesse sentido, a hipótese é de que a mediação, concebida enquanto meio de enfrentamento de conflitos realizado entre os próprios participantes, sob auxílio de um terceiro imparcial, que não possui poder decisório na condução da possível resolutiva, apresenta-se com potencial de desinvisibilização de sujeitos, na medida em que lhes proporciona identificar, conduzir e desenvolver, autônoma e dialogicamente, soluções para suas controvérsias.

A mediação, ao viabilizar a construção dialógica dos rumos das controvérsias, parece privilegiar e respeitar os saberes e os desejos dos envolvidos, de forma a desconsiderar as propostas tradicionais de realização de justiça, ancoradas em discursos epistemológicos hegemônicos, que aparentam-se inadequados, sobretudo quando incoerentes ou incompatíveis com as expressões volitivas que ascendem dos próprios atores.

Nessa toada, a teoria do pensamento pós-abissal, ao preconizar a construção de uma contra epistemologia, que nega a existência de uma epistemologia geral e, por conseguinte, 
reconhece a pluralidade de saberes, existente para além do saber monolítico universalizante, pode somar-se à perspectiva de compreensão da mediação enquanto técnica apta a abarcar a multiplicidade de fontes e de configurações de saberes e de vontades.

Dessa forma, imperiosa se faz a análise da natureza e da forma de condução procedimental da mediação como possível ferramenta contra hegemônica, quando judicialmente realizada. Para tanto, almeja-se (i) aferir o pensamento abissal enquanto linha divisória de segregação e opressão; (ii) decompor a exposição do trato legislativo conferido à mediação; e, (iii) empreender a averiguação da sua eventual contribuição para a desinvisibilização dos sujeitos envolvidos à luz da teoria do pensamento pós-abissal, tornamse complementares.

Cumpre, ainda, salientar que o estudo é realizado sob a vertente teórico-dogmática, através de raciocínio hipotético-dedutivo e investigação jurídico-descritiva, pelo que a utilização de dados coletados em fonte bibliográfica terá crucial relevância.

A conjectura teórica na condução do trabalho é a teoria do pensamento pós-abissal, apresentada por Boaventura de Sousa Santos (2009), que propõe a construção de uma contra epistemologia, que nega a existência de uma epistemologia geral e, por conseguinte, reconhece a pluralidade de saberes, existente para além do saber monolítico universalizante.

Nesse sentido, destaca-se que a relevância da pesquisa é atribuída à possível popularização da mediação enquanto método de enfrentamento de conflitos, motivo pelo qualo estudo pode contribuir para sugerir possibilidades comunicativas para a aplicação do procedimento, por meio de uma atuação colaborativa e pluriepistêmica entre todos os envolvidos.

\section{PENSAMENTO PÓS-ABISSAL: SUPERAÇÃO DO MODELO MONOLÍTICO UNIVERSALIZANTE E DA LINHA ABISSAL DE SEGREGAÇÃO E DE OPRESSÃO SOCIAIS}

A modernidade ocidental é marcada por uma linha invisível de divisão, que segrega, subalterniza e oculta, desde a colonialização da América, em 1492 (DUSSEL, 1993), tudo que extrapola os arquétipos identitários etnocêntricos, o que alcança convicções e juízos de valores, de civilidade e de normalidade, bem como padrões sociais e culturais forçosamente binários. 
Nesse sentido, emerge a linha abissal da desigualdade, de modo que, para cada lado dessa linha divisória, existem oposições estruturais, econômicas, políticas e culturais, ou seja, universos distintos, que podem ser nomeados como, de um lado, as metrópoles (modernas) ou Norte-Global e, do outro, as colônias (modernas) ou Sul-Global ${ }^{3}$. E, embora sejam nítidas as desigualdades sociais que permeiam a divisão, a elas antecede uma desigualdade epistêmica, na medida em que a força opressora dominante extermina outras versões epistemológicas.

Desse modo, ao subcategorizar as fontes externas de conhecimentos (obviamente, fontes oriundas do universo colonial/Sul-Global, reduzindo-as às reminiscências do passado e, por conseguinte, propagando sua imprestabilidade na contemporaneidade, especialmente, diante do discurso técnico-científico como fonte exclusiva de legitimação de saberes), liquidam-se quaisquer possibilidades de coexistência (paritária) de culturas e saberes alheios à ciência moderna.

\begin{abstract}
O pensamento moderno ocidental é um pensamento abissal. Consiste num sistema de distinções visíveis e invisíveis, sendo que as invisíveis fundamentam as visíveis. As distinções invisíveis são estabelecidas através de linhas radicais que dividem a realidade social em dois universos distintos: o universo "deste lado da linha" e o universo "do outro lado da linha". A divisão é tal que "o outro lado da linha" desaparece enquanto realidade, torna-se inexistente, e é mesmo produzido como inexistente. Inexistência significa não existir sob qualquer forma de ser relevante ou compreensível. Tudo aquilo que é produzido como inexistente é excluído de forma radical porque permanece exterior ao universo que a própria concepção aceite de inclusão considera como sendo o Outro. A característica fundamental do pensamento abissal é a impossibilidade da co-presença dos dois lados da linha. Este lado da linha só prevalece na medida em que esgota o campo da realidade relevante. Para além dela há apenas inexistência, invisibilidade e ausência não-dialectica. (SANTOS, 2007 p. 03-04).
\end{abstract}

Nesse sentido, o domínio epistemológico Norte-Global parece transpor sua limitação histórico-colonial, de forma a manter-se ativo ainda que superados os processos de independência política das colônias para com suas metrópoles (MENESES, 2008, p. 10). Logo, todo êxito da estruturação de esquecimento, inexistência e invisibilidade dos saberes primários, genuínos e endogenamente existentes no Sul-Global perdura nos dias atuais.

Verdade é que a construção hegemônica, que permeia a história, a cultura e o conhecimento, é a problemática mais singela, sutil e poderosa no cenário de desigualdades

\footnotetext{
${ }^{3}$ Aqui as designações "Metrópole-Colônia” / "Norte-Sul” possuem categorização político-sociológica, e não, meramente, geopolítica, tradicional, evidenciando as nações e as comunidades afluentes e privilegiadas do mundo transnacionalizado por oposição àquelas que seriam econômica e politicamente marginalizadas.
} 
globais, na medida em que constitui-se alicerce de justificativa epistemológica moderna para todas as demais violências, opressões e segregações sociais enfrentadas.

Com efeito, decolonizar o pensamento (abissal) emerge como mecanismo hábil não apenas à desconstrução das hierarquias entre os saberes, mas também aos enfrentamentos diante das dominações econômica, política e cultural. Afinal, o conhecimento, em suas múltiplas formas, não está equitativamente distribuído na sociedade e tende a estar tanto menos quanto maior é o seu privilégio epistemológico, pelo que a injustiça social se traduz, frequentemente, em injustiça cognitiva (SANTOS, 2010, p.17/42).

\begin{abstract}
Deste modo, a problemática da pós-colonialidade passa por uma revisão crítica de conceitos hegemonicamente definidos pela racionalidade moderna, como sejam história, cultura ou conhecimento, a partir de uma perspectiva e condição de subalternidade. Como os ensaios que integram esta edição revelam, revisitar estes conceitos integra várias exigências: a histórica, ou seja, a necessidade de repensar todos os passados e perspectivas futuras à luz de outras perspectivas, que não as do Norte global; a ontológica, que passa pela renegociação das definições do ser e dos seus sentidos; e, finalmente, a epistémica, que contesta a compreensão exclusiva e imperial do conhecimento, desafiando o privilégio epistémico do Norte global. (MENESES, 2008, p. 06).
\end{abstract}

A contestação ao privilégio cognitivo Norte-Global, de ditar verdades e tornar-se fonte exclusiva e imperial de conhecimento, torna-se, então, talvez o mais importante ato de resistência contra a colonialidade imposta aos invisibilizados, de modo que a ascensão de epistemologias endógenas, isto é, epistemologias do Sul-Global, podem propiciar a congregação e dialogicidade de novos e inesgotáveis saberes e conhecimentos; o que, então, pode ser materializado como pensamento pós-abissal.

O pensamento pós-abissal parte da ideia de que a diversidade do mundo é inesgotável e que esta diversidade continua desprovida de uma epistemologia adequada. Por outras palavras, a diversidade epistemológica do mundo continua por construir. (SANTOS, 2009, p. 44).

O pensamento pós-abissal propaga a superação do modelo monolítico universalizante de saber pelo pluralismo epistemológico, na medida em que restaura, fomenta e dissemina, em paridade de importância e presteza, todas as formas e fontes de conhecimento para além da ciência, teologia e filosofia (SANTOS, 2007, p. 73). Logo, confere-se visibilidade aos 
conhecimentos populares, leigos, plebeus, camponeses, indígenas etc., posto que o desafio à hegemonia cultural perpassa pela abertura à diversidade de saberes (MENESES, 2008, p. 07).

Lado outro, a superação da hierarquia cognitiva gera repercussões nas demais esferas de opressão e segregação, visto que, a partir da emancipação epistemológica decorrente do pensamento pós-abissal, desinvisibilizam-se saberes, mas também os mentores desses saberes, de modo que as justificativas etnocêntricas para a subalternidade e a ocultação não mais se frutificam e as insurgências, diante dos estigmas de sub-humanidade e das violências sociais, adquirem, igualmente, indelével visibilidade.

Nessa feita, a desinvisibilização Sul-Global e, por conseguinte, o reconhecimento de diversos grupos sociais, torna-se praticável com a superação de um paradigma teórico, que naturaliza a desigualdade social e a consequente produção de "subcidadãos" como um fenômeno de massa (SOUZA, 2006, p.23).

Assim, refletir e forjar um pensamento crítico, construído a partir da práxis das sociedades emergentes, capaz, pois, de viabilizar novos conceitos, categorias, representações e instituições sociais (WOLKMER, 2006, p. 88), apresentam-se como possíveis alternativas epistêmicas para a construção de uma cultura político-jurídica mais democrática e efetivamente marcada pelo pluralismo e pela alteridade Sul-Global.

Nesse ínterim, a valorização de saberes multifacetados adquire importância ímpar no cenário Sul-Global, de forma que a ruptura com os modelos estruturais tradicionais, modernos e, portanto, hegemônicos - ou, ao menos, a releitura desses modelos - é crível para a endogenia almejada.

Assim, a mediação, ainda que oficialmente (e, portanto, historicamente) etnocêntrica (CACHAPUZ, 2003, p. 24; MOORE, 1998, p. 32), enquanto ferramenta hábil à resolução de conflitos, pode contribuir para a transposição ontológica e epistêmica da linha abissal. Afinal, tal estratégia de realização de justiça pressupõe um redesenho dos papéis das pessoas envolvidas e a refundação de seus contextos, bem como uma ratificação dos conhecimentos e visões de mundo, que são tipicamente locais. Vale dizer, se a mediação pode buscar privilegiar a autonomia privada, consagrada pelo viés da voluntariedade que é amplamente sufragado pelas normativas nacionais pertinentes, ela, igualmente, pode propiciar a desinvisibilização dos sujeitos, conferindo importância e presteza às suas expressões volitivas pluriepistêmicas, de 
forma a suplantar as soluções jurisdicionais tradicionais, quando incompatíveis com a opção dos atores.

Significa que a perspectiva de mediação como forma adequada de superação de conflito não apenas a torna disponível, como deixa aberto o caminho para que quaisquer outros enredos resolutivos possam ser implementados ou propostos.

Ademais, a voluntariedade é corolário da autonomia privada como fonte dos significados, da estrutura (que é fatalmente plástica), dos processos (que se definem, contextualmente, pelo movimento que considera as posições dos demais atores) e das funções (eis que aos participantes pode ser facultada a decisão, inclusive, acerca da opção de eleger a mediação como técnica de solução ou de gestão de conflitos).

Em tudo isso, nota-se a possibilidade robusta da afirmação do protagonismo de pessoas e de grupos ou povos, de suas identidades históricas e culturais de conformação livre e contínua, de seus saberes e, portanto, de seus universos.

E, a mediação, como expressão da vontade dos participantes, em que a elas é oportunizado o momento de fala, em concomitância à qualificação da escuta pelos interlocutores, permite, não apenas a construção de uma resolutiva endógena satisfatória, como também o protagonismo aos atores, transpondo o abissal, de forma a auto afirmá-los como sujeitos construtores dos próprios direitos.

A explanação, contudo, da aplicação procedimental e da sua condução, quando havida no bojo do Poder Judiciário, descortinam-se como pontos focais para aferir o potencial de contribuição da mediação judicial, para a desinvisibilização dos envolvidos. Cabe averiguar se, nesse âmbito, a mediação ainda preserva seu potencial de êxito na colaboração para a visibilidade, o que se constata apenas se as opções pessoais são respeitadas, mesmo quando conflitantes com a resposta jurisdicional pré-concebida como justa e legítima e, portanto, quando contra hegemônica.

\section{ACESSO À JUSTIÇA E À ORDEM JURÍDICA JUSTA}

A prestação jurisdicional possui respaldo constitucional de direito fundamental no Brasil, de modo que no bojo estrutural normativo há expressa proteção aos cidadãos para provocarem o Poder Judiciário diante de lesão ou ameaça a direito (BRASIL, 1988), pelo que 
o socorro pela jurisdição Estatal apresenta-se, até então, como caminho certo para dirimir todas as controvérsias.

\begin{abstract}
Ocorre que, paralelamente ao entendimento de que cabe ao Judiciário a responsabilidade pela resolução das querelas da sociedade, criou-se também a compreensão de que somente cabe ao Estado o poder de dirimir os problemas da população, não tendo esta a capacidade natural de solucionar sem traumas parte de seus problemas comuns. (ARAÚJO, 1999, p. 127 -128).
\end{abstract}

Ora, o Estado, possuindo o monopólio da jurisdição, tem o “dever” de demonstrar à sociedade quais são os seus direitos, a fim de que ela, por si só, busque a consecução dos mesmos. No entanto, quando ocorrem conflitos no bojo da sociedade e esta não consegue resolvê-los sozinha, o Estado intervém, com o fito de que haja a composição entre os envolvidos e, consequente, pacificação social.

Desse modo, a intervenção estatal para elidir qualquer conflito, tradicionalmente conhecida como jurisdição, é compreendida por Ada Pellegrini Grinover como "uma das funções do Estado, mediante a qual este se substitui aos titulares dos interesses em conflito para buscar a pacificação do conflito que os envolve, com justiça". (GRINOVER, 2007, p.145).

Giuseppe Chiovenda completa:

(...) função do estado que tem por escopo a atuação da vontade concreta da lei por meio da substituição, pela atividade de órgãos públicos, da atividade de particulares ou de outros órgãos públicos, já no afirmar a existência da vontade da lei, já no tornála, praticamente, efetiva. (CHIOVENDA, 1969, p.76).

Fato é que “a jurisdição, apesar de ser considerada monopólio do Estado, não pode ser considerada monopólio do Poder Judiciário ou a única forma de se resolverem conflitos” (RODRIGUES JÚNIOR, 2007, p. 126); restando infrutífero impetrar apenas ao Poder Judiciário o único caminho de acesso à justiça e à ordem jurídica justa.

Assim, edifica-se uma concepção diversa de acesso à justiça, alicerçada na aliança entre o Estado e a sociedade, objetivando a resolução de conflitos por meio de mecanismos outros, rompendo, por conseguinte, a exclusividade dos tribunais.

A concepção de acesso à justiça sofre um alargamento, incorporando-se ao poder-dever do Estado de “dizer o direito” outros mecanismos, igualmente legítimos. Nesse diapasão, à 
jurisdição é reservada a condição de última ratio (RODRIGUES JÚNIOR, 2007, p. 127), de modo que a hegemonia dirigida à prestação jurisdicional judicial é rompida com a ascensão dos métodos de superação de conflitos, tais como a mediação, a conciliação e a arbitragem.

Nessa seara, fortifica-se a ideia da aplicação desses métodos por significarem o "acesso à manifestação e à orientação jurídica e a todos os meios alternativos de composição de conflitos.” (MARINONI, 2000, p. 28), de forma que, pelo escopo do trabalho, há limitação de exposição à mediação judicial, haja vista que se pretende refletir acerca de seu potencial enquanto estratégia de colaboração para a transposição do abismo que reafirma opressões e segregações do pensamento abissal.

\title{
4 A MEDIAÇÃO COMO ALTERNATIVA CONTRA HEGEMÔNICA E PLURIEPISTÊMICA DE PROFERIR O DIREITO
}

A mediação é compreendida como mecanismo de superação de conflitos realizado pelos próprios envolvidos, auxiliados por um terceiro imparcial, que não possui poder decisório na condução do possível encaminhamento da controvérsia, mas que estimula os envolvidos a identificar ou desenvolver alternativas construídas dialogicamente. (BRASIL, 2015).

Luís Alberto Warat complementa:

\begin{abstract}
A mediação é uma forma ecológica de resolução dos conflitos sociais e jurídicos; uma forma na qual o intuito de satisfação do desejo substitui a aplicação coercitiva e terceirizada de uma sanção legal. A mediação como uma forma ecológica de negociação ou acordo transformador das diferenças. (WARAT, 2001, p. 23).
\end{abstract}

Nesse sentido, e percebendo o procedimento como atividade técnica em que os envolvidos possuem todo poderio decisório, na medida em que a autonomia da vontade dos atores é soberana, e o terceiro ali presente é imparcial e mero condutor do procedimento de comunicação (BRASIL, 2015), acredita-se que as pessoas participantes adquirem visibilidade e protagonismo para com seus saberes e seus desejos.

Juan Carlos Vezzulla, então, acrescenta:

[...] mediação é a técnica privada de solução de conflitos que vem demonstrando, no mundo, sua grande eficiência nos conflitos interpessoais, pois com ela, são as próprias partes que acham as soluções. O mediador somente as ajuda a procurá-las, 
introduzindo, com suas técnicas, os critérios e os raciocínios que lhes permitirão um entendimento melhor. (VEZZULLA, 1998, p. 15-16).

Ademais, considerando a condução dialógica e paritária do procedimento, em que os atores podem ser encorajadas a expor suas razões e desejos de forma genuína e própria, com menos atropelos do formalismo e do tradicionalismo exacerbados da jurisdição convencional, o cenário para construção de uma possível superação do conflito apresenta-se mais simplista, abrangente, inclusiva e, por conseguinte, contra hegemônica.

É essa visão que permite que o conflito possa ser percebido como inerente à convivência social e como oportunidade à construção de identidades e ao reconhecimento do outro.

Não sem razão, a pretensão precípua da mediação, pelo menos em sua alardeada vertente transformadora, não é, necessariamente, resolver a controvérsia entabulada, mas restaurar o diálogo corrompido ou interrompido entre os envolvidos e, consequentemente, as relações adjacentes, pelo que o procedimento não tem um fim em si mesmo, mas possui caráter instrumental para dirimir ou gerir conflitos que, por vezes, são essencialmente afetivos. É oportuno o escólio de Luís Alberto Warat:

\begin{abstract}
A mediação começa quando as partes conseguem interpretar, no simbólico, ódios e amores que as diferenciam. A mediação facilita às partes a possibilidade de interpretar seus ódios e amores. O que é mediável são os conflitos de afetos, não as diferenças patrimoniais sem história, sem afetos, nem desejo (elas são transações que podem estar disfarçadas de mediações). Nos casos patrimoniais sem história, se decidem as diferenças, não existe conflito a resolver. Para que algo possa ser mediado, é necessário que uma das partes, pelo menos, tenha um conflito de ódio, amor ou de dor. (WARAT, 2001, p. 24).
\end{abstract}

Vale dizer, se a mediação pode versar sobre todo o conflito ou parte dele (BRASIL, 2015), o encaminhamento parcial, mesmo sem por termo à controvérsia, pode proporcionar solicitude, prestatividade e cortesia entre os mediados para prosseguirem e restabelecerem o convívio harmônico. Construir uma resposta para o conflito torna-se, portanto, uma consequência decorrente da (eventual) restauração de vínculo afetivo ou interação dialética, obtidos com o procedimento.

Nessa toada, a condução da mediação não deve ser realizada de forma superficial e em busca de composições a todo custo, mas dirigida em atenção aos conflitos sociológicos de ódio, amor ou dor que se escondem por trás da problemática jurídica. 
Frise-se: o êxito do procedimento não deve ser balizado pela quantidade de acordos celebrados, mas pelo grau de satisfação dos envolvidos com o resultado e com o procedimento, sendo, inclusive, esse o teor do Enunciado $n^{\circ} 22$, aprovado na I Jornada "Prevenção e Solução Extrajudicial de Litígios”, promovida pelo Centro de Estudos do Conselho da Justiça Federal, a saber:

Enunciado no 22. A expressão "sucesso ou insucesso" do art.167, § $3^{\circ}$, do Código de
Processo Civil não deve ser interpretada como quantidade de acordos realizados, mas
a partir de uma avaliação qualitativa da satisfação das partes com o resultado e com o
procedimento, fomentando a escolha da câmara, do conciliador ou do mediador com
base nas suas qualificações e não nos resultados meramente quantitativos. (BRASIL,
2016).

Ademais, a mediação é estruturada, principiologicamente, pela imparcialidade do mediador; isonomia entre as partes; oralidade; informalidade; autonomia da vontade das partes; busca do consenso; confidencialidade; e, boa-fé (BRASIL, 2015); sem prejuízo do princípio da decisão esclarecida, o que torna ainda mais perceptível o potencial contra hegemônico do procedimento.

A imparcialidade do mediador é condição para a preservação do protagonismo dos envolvidos. Mesmo que seja preconizada, há de se reconhecer o risco de, na mediação judicial, opções menos comuns ou menos atinentes a padrões decisórios hegemônicos serem pouco compreendidas e até mesmo rechaçadas. Assim, a imparcialidade dá destaque ao desafio dos facilitadores do diálogo e da condução da controvérsia, para que se dispam de suas vestimentas epistêmicas arraigadas no modelo mais consagrado no direito herdado dos colonizadores e cultivado pela universalização das fontes dos saberes.

A isonomia deve ser interpretada como igualdade, em suas mais amplas feições. Igualdade impõe o fomento da paridade, para o exercício autônomo de liberdades. Somente nesse foco que invisibilizados podem desocultar-se.

A oralidade e a informalidade são convites à transgressão e à resistência, mas também à coautoria dos enredos de esquemas de superação de celeumas.

Ademais dos outros princípios, a boa-fé, de cunho objetivo, importa à mediação no que toca às suas múltiplas funções, destacando-se, dentre elas, os papéis de vedação ao abuso de direito e da imposição do exercício colaborativo, cooperativo e probo das práticas dialógicas. 
É nesse rumo que a boa-fé pode engendrar a consideração das pessoalidades, pelos envolvidos, no cerne da relação.

Logo, o estímulo à expansão do método parece favorável à desocultação dos sujeitos, que, inclusive, podem não buscar o socorro jurisdicional, muitas das vezes, em razão do excesso de formalidade e de sofisticação que permeia todo Poder Judiciário - o que alcança formações positivistas-legalistas, vocábulos rebuscados, estrutura burocratizada e vestimentas excessivamente formais; atmosfera possivelmente pouco confortável para pessoas não familiarizadas com essas abordagens.

Desde 1827, com a fundação da Academia de Direito de São Paulo, os cursos de direito tiveram seu papel relevante na formação dos atores jurídicos dos locais de exercício do poder. [...] Os cursos, desde então, restringiram-se a uma visão positivista-legalista do fenômeno jurídico, consolidando uma postura pedagógica marcada pela glosa dos textos legais, sem qualquer preocupação crítico-reflexiva. A formação normativa expressa, muitas vezes, por argumentos de autoridade, aliada às relações pautadas na medição de forças e no litígio, dificultam a democratização do acesso à Justiça e a participação efetiva do cidadão na condução da solução dos conflitos. O Direito escrito e formalizado da moderna sociedade burguês-capitalista alcança o apogeu com sua sistematização científica, representada pela Dogmática Jurídica. O paradigma da Dogmática Jurídica forja-se sobre proposições legais abstratas, impessoais e coercitivas, formuladas pelo monopólio de um poder público centralizado (o Estado), interpretadas e aplicadas por órgãos (Judiciário) e por funcionários (os juízes) [...] Embora a dogmática jurídica estatal se revele, teoricamente, resguardada pelo invólucro da cientificidade, competência, segurança, na prática intensifica-se a gradual perda de sua funcionalidade e de sua eficácia. (WOLKMER, 2001, p. 59).

Assim, cabe reafirmar que, ao mesmo tempo em que a mediação pode representar alternativa epistêmica de concreção ou consecução de justiça, é mister o rompimento com posturas acadêmicas tradicionais, execessivamnete formalistas e não plurais, que implementam a exclusão e, por vezes, impedem o acesso à justiça, compreendida de modo amplo. Quanto à necessidade de mudança na formação jurídica, Cappelletti e Garth sugerem:

Nenhum aspecto de nossos sistemas jurídicos modernos é imune à crítica. Cada vez mais pergunta-se como, a que preço e em benefício de quem estes sistemas de fato funcionam. Essa indagação fundamental que já produz inquietação em muitos advogados, juízes e juristas torna-se tanto mais perturbadora, em razão da invasão sem precedentes dos tradicionais domínios do Direito, por sociólogos, antropólogos, economistas, cientistas políticos e psicólogos, entre outros. Não devemos, no entanto, resistir a nossos invasores; ao contrário, devemos respeitar seus enfoques e reagir a eles de forma criativa. Através da revelação do atual modo de funcionamento de nossos sistemas jurídicos, os críticos oriundos das outras ciências sociais podem, na

Revista Cidadania e Acesso à Justiça | e-ISSN: 2526-026X | Maranhão | v. 3 | n. 2 | p. 61 - 78 | Jul/Dez. 2017. 
realidade, ser nossos aliados na atua fase de uma longa batalha histórica - a luta pelo ‘acesso à justiça’. (CAPPELLETTI, GARTH, 1988, p. 8).

Assim, a mediação, ao viabilizar uma construção dialógica para a solução das controvérsias na luta pelo acesso à justiça, subvertendo a lógica hegemônica da cultura do litígio, privilegia e respeita os saberes e os desejos dos envolvidos, de forma a desconsiderar as alternativas tradicionais, quando incoerentes ou incompatíveis com as expressões volitivas que ascendem dos próprios mediados.

Vale, ainda, salientar que, sendo os meios de solução de conflitos concebidos como possibilidades plurais à prestação jurisdicional tradicional, relativamente à mediação, deve-se preservar a essência identitária do procedimento, no que respeita à firmação de pressupostos para a sua flexibilidade. Para tanto, pressupõem-se condução pacífica e intimista, além da qualificação de escuta às efetivas querelas sociais, na esteira dos conteúdos deônticos de seus princípios fundantes.

Mesmo porque, à contrário senso, a distorção e/ou formatação das soluções trazidas hegemonicamente podem replicar o papel desempenhado pelas decisões judiciais na imposição de arquétipos menos suscetíveis ao protagonismo dos atores do conflito e de suas particularidades. Tais pressupostos podem minimizar as máculas da significação epistemológica do feito e, por conseguinte, o silenciamento dos invisibilizados. A essas pessoas, parece caber mais que a caridade e o paternalismo Estatal.

Não sem razão, Sales e Chaves (2014, p. 260) discorrem sobre a importância da capacitação para a realização da mediação.

\footnotetext{
A mediação de conflitos, por sua vez, apesar de não fortemente expressa em lei, ganhou destaque nacional com a Resolução n. 125, do CNJ/2010, que já previu claramente a exigência de capacitação. Um dos maiores problemas enfrentados na capacitação e na implementação desses mecanismos consensuais de solução de conflitos no Brasil é a confusão de conceitos e de suas práticas. (SALES, CHAVES, 2014, p. 260).
}

Significa que, para engendrar alternativas efetivas, à mediação judicial deve preceder a capacitação de mediadores judiciais, para a superação dos vícios e dos condicionamentos epistêmicos e para o aprimoramento das técnicas de juízo conciliatório.

Isso porque, sendo os juízes imbuídos de todo poder decisório nos processos sob sua jurisdição, ao conduzirem procedimentos de mediação, a força impositiva, peculiar da práxis a 
eles cotidianamente imposta, pode sobressair-se à atividade técnica supostamente dotada de imparcialidade na construção particular de superação da controvérsia.

Nesse diapasão, Márcio Túlio Viana, ao argumentar acerca do exercício jurisdicional e de toda a sua estruturação hierarquizante, etnocêntrica e discriminatória, assevera:

\begin{abstract}
Vejo hoje, com vinte e um anos de atraso, que o processo - ou o procedimento - é algo muito mais intrincado e complexo do que um simples conjunto de regras formais, entre as quais o juiz se movimenta. Não é apenas um composto de prazos, recursos, sentenças, petições. É também o modo de falar, o jeito de ouvir, a forma de olhar; são as vestes talares, o estrado alto, o linguajar rebuscado, o argumento mais hábil. É tudo isso e muito mais: como as raízes de uma árvore, ele se irradia para além dos papéis, para além da lei e para fora da sala de audiências. Se o que não está nos autos não está no mundo, o que está no mundo está sempre nos autos... Por isso, discriminamos todos nós, juízes, quando não notamos que todas as coisas se interagem; e que a Justiça não é uma estátua de mármore, mas uma mulher cheia de malícias, que recebe e reflete tudo o que se passa fora dela. Em poucas palavras, discriminamos quando não percebemos que as relações de dominação não se esgotam no pequeno mundo da fábrica, mas acompanham o trabalhador em cada um de seus passos e de seus gestos; que o perseguem até em seu lar, quando ele engole e digere, sem defesas, os jornais e as domingadas da TV... Discriminamos todos nós quando não vemos - ou tentamos não ver - que a igualdade formal, embora muito importante, pode também servir, e tem servido, para mascarar e legitimar a desigualdade real: se todos são iguais, por que não o seriam as próprias regras? Na verdade, como dizia, as regras compensatórias, que a lei criou, só reduzem as discriminações mais visíveis. Discriminamos todos nós, eu diria, quando deixamos de ser parciais: não para destorcer a prova, ignorar a norma ou prejulgar o fato, mas no sentido de compensar, na medida do possível e do razoável, as outras tantas discriminações que a lei despreza ou esconde - pois ela quer manter o mito, e (graças a isso) todo o sistema. Discriminamos todos nós, enfim, quando nos tornamos insensíveis às infinitas variáveis do cotidiano, sem perceber que uma parte do processo vem das ruas contaminando, por todos os lados, o corpo cheio de poros da Justiça. (VIANA, 1998, p. 177).
\end{abstract}

Portanto, a busca do entendimento e do consenso, bem como a facilitação da resolução do conflito (BRASIL, 2015), de forma imparcial, deve ser à base de atuação do mediador; de maneira que, quaisquer desvios ou ingerências de terceiros, ainda que togados, viciam a mediação e, por conseguinte, ceifam a possibilidade de desinvisibilização dos mediados. Afinal, o protagonismo volitivo a eles conferido - e sua respectiva expressão contra hegemônica, pode corromper-se pelo saber monolítico universalizante, ainda tão presente na práxis jurídica, repristinando, em última perspectiva, a linha abissal de segregação e de opressão por eles superável.

Revista Cidadania e Acesso à Justiça | e-ISSN: 2526-026X | Maranhão | v. 3 | n. 2 | p. 61 - 78 | Jul/Dez. 2017. 


\section{CONSIDERAÇÕES FINAIS}

No teste, em abstrato, da hipótese teórica de serventia da mediação como mecanismo contra hegemônico e pluriepistêmico, constata-se que essa forma de gestão e de superação de entraves de convivência parece ter potencial para revelar caminhos plurais, que admitem o protagonismo dos atores do conflito; fontes múltiplas de integração e produção de seu arquétipo; significados plásticos a depender do grupo e das subjetividades que a articulam; processos menos rígidos para assegurar espaços de liberdade de construção de seu formato e de sua adesão; funções próprias que transcendem a mera implementação de um acordo ou de uma solução imediatista e superficial, tudo na esteira da possibilidade de compreensão e enfrentamento da lide sociológica e de sua inserção fenomenológica.

A proposição de alternativas pluri-epistêmicas que permitam a desocultação de tudo aquilo que a modernidade indolente se encarregou de encobrir, desde 1492, é condição sine qua non de um diálogo multicultural dialético e inclusivo. Esse movimento de resistência tem seu êxito dependente da possibilidade efetiva de reestruturação de uma ordem jurídica que contenha mecanismos hábeis para que todos os seus membros satisfaçam, ao menos, suas necessidades básicas e desenvolvam suas capacidades e planos de vida de maneira salutar, paritária e compatível com sua cultura e com seus desejos.

Os meios adequados de resolução de conflitos, especialmente a mediação, apresentamse como possíveis ferramentas para essa desocultação. Afinal, em uma perspectiva externa à relação que se estabelece entre os atores envolvidos em controvérsias de convivência, tais meios adequados diversos de solução podem representar a configuração que é refratária aos procedimentos tradicionalmente ligados ao Poder Judiciário.

Noutro rumo, numa ótica interna à relação, esses mecanismos de superação de celeumas podem propiciar o resgate de vínculos sociais e de afinidade, a visibilidade das pessoas interessadas e a afirmação de sua autonomia de gestão e de decisão para os rumos do conflito, implementando o deslocamento significativo do protagonismo para “dizer o direito”.

Nesse sentido, compreendida enquanto meio adequado, apesar de diverso, de gestão e/ou solução de conflitos, articulada pelas próprias pessoas envolvidas ou interessadas, a mediação pode mitigar os elementos heterônomos (que tendem a ser hegemônicos), na medida em que os interessados podem ser auxiliados por um terceiro imparcial, sem poder decisório. 
Assim, se a mediação pode ser percebida como incentivo importante para o exercício democrático de autonomia privada por pessoas em entraves de convivência, é bem verdade que, igualmente, pode revestir-se de potencial de desinvisibilização de sujeitos, visto que lhes proporciona liberdade para identificar, conduzir e desenvolver, dialogicamente, soluções para seus anseios de justiça, figurando, então, como sujeitos construtores do próprio direito.

Desse modo, a mediação, ao privilegiar o não deslocamento e a não subordinação dos interessados a sujeitos e contextos estranhos às suas querelas, dá azo à manifestação do pensamento e da vontade, direcionada à composição multiforme e pluriautoral de soluções de superação ou gestão de desentendimentos.

Esse panorama, que não se reveste das mesmas formalidades e rigores próprios do Poder Judiciário, pode, portanto, desconsiderar ou, pelo menos, afastar-se dos ritos tradicionais e hegemônicos, sobretudo quando são incoerentes ou incompatíveis com a escolha dos participantes. Daí, a mediação apresenta-se como possível mecanismo contra epistêmico, de modo a favorecer e a efetivar a multiplicidade de fontes e configurações de saberes, isto é, o pluralismo epistêmico.

Portanto, e a fim de preparar, fortalecer e ampliar o espectro do que se compreende como justiça, mesmo que esse movimento aconteça no âmbito do Poder Judiciário enquanto condutor da mediação judicial, cabe engendrar alternativas em desfavor da segregação abissal e das invisibilidade adjacentes, para a efetivação do acesso à justiça e a uma ordem jurídica justa.

\section{REFERÊNCIAS}

ARAUJO, Luís Alberto Gómez. Os mecanismos alternativos de solução de conflitos como ferramentas na busca da paz. In: Mediação - métodos de resolução de controvérsias, n. 1, coord. Ângela Oliveira. São Paulo: LTr, 1999, p.127 - 132.

BRASIL. Constituição (1988). Constituição da República Federativa do Brasil de Brasília, Diário Oficial da União, Brasília, 05 de out. 1988. Disponível em:

$<$ http://www.planalto.gov.br/ccivil_03/constituicao/constituicao.htm> Acesso em: 10 de Ago. 2017.

BRASIL. Enunciado n. 22, de 22 e 23 de agosto de 2016. I Jornada Prevenção e Solução Extrajudicial de Litígios - Centro de Estudos. Conselho da Justiça Federal. 2016. Disponível em: < http://www.fecema.org.br/arquivos/1642>. Acesso em: 10 de Ago. 2017. 
BRASIL. Lei Federal n. 13.140, de 26 junho de 2015. Dispõe sobre a mediação entre particulares como meio de solução de controvérsias e sobre a autocomposição de conflitos no âmbito da administração pública, e dá outras providências. Diário Oficial da União. 2015. Disponível em: < http://www.planalto.gov.br/ccivil_03/_ato20152018/2015/Lei/L13140.htm>. Acesso em: 10 de Ago. 2017.

BRASIL. Resolução n. 125, de 29 de novembro de 2010. Dispõe sobre a Política Judiciária Nacional de tratamento adequado dos conflitos de interesses no âmbito do Poder Judiciário e dá outras providências. Conselho Nacional de Justiça. 2010. Disponível em:

<http://www.cnj.jus.br/busca-atos-adm?documento=2579>. Acesso em: 10 de Ago. 2017.

CACHAPUZ, Rozane da Rosa. Mediação nos Conflitos \& Direito de Família. Curitiba: Juruá, 2003.

CAPPELLETTI, Mauro; GARTH, Bryant. Acesso à justiça. Tradução de Ellen Gracie Northfleet. Porto Alegre: Fabris, 1988.

CHIOVENDA, Giuseppe. Instituições de Direito Processual Civil. Vol. II, trad. Bras. de J. Guimarães Menegale, $3^{\text {a }}$ edição, São Paulo: ed. Saraiva, 1969.

DUSSEL, Enrique. 1492: o encobrimento do outro. A origem do "mito da modernidade". Petrópolis: Vozes, 1993.

GRINOVER, Ada Pellegrini; DINAMARCO, Cândido; CINTRA, Antônio. Teoria Geral do Processo. 23 Edição. São Paulo: Malheiros Editores, 2007.

MARINONI, Luiz Guilherme, ARENHART, Sérgio Cruz. Comentários ao Código de Processo Civil. São Paulo: Revista dos Tribunais, 2000.

MENESES, Maria Paula. Epistemologias do Sul. Revista Crítica de Ciências Sociais [Online], 80, Março 2008, p. 05-10.

MOORE, Christopher W. O processo de mediação: estratégias práticas para a resolução de conflitos. Porto Alegre: Artmed, 1998.

RODRIGUES JÚNIOR, Walsir Edson. A prática da mediação. In: FIUZA, César; NAVES, Bruno Torquato de Oliveira; SÁ, Maria de Fátima Freire (Coord.). Direito Civil: atualidades. Belo Horizonte: Del Rey, 2003.

SALES, Lilia Maia de Morais; CHAVES, Emmanuela Carvalho Cipriano. Mediação e Conciliação Judicial - A Importância da Capacitação e de seus Desafios. Seqüência (Florianópolis), n. 69, Dez. 2014, p. 255-280.

SANTOS, Boaventura de Sousa. A crítica da razão indolente: contra o desperdício da experiência. São Paulo: Cortez, 2000. 
SANTOS, Boaventura de Souza. A gramática do tempo: por uma nova cultura política. $3^{\mathrm{a}}$ ed. São Paulo: Cortez, 2010.

SANTOS, Boaventura de Souza. (org.). Conhecimento Prudente para uma vida Decente. São Paulo: Cortez, 2004.

SANTOS, Boaventura de Souza. (org.); MENESES, Maria Paula (org.). Epistemologias do Sul. São Paulo: Cortez, 2010.

SANTOS, Boaventura de Souza. Para além do Pensamento Abissal: das linhas globais a uma ecologia de saberes. Revista Crítica de Ciências Sociais [Online], 78, Out. 2007, p. 03-46.

SANTOS, Boaventura de Souza. Pensar el Estado e la sociedade: desafios actuales. Buenos Aires: Waldhuter Editores, 2009.

SANTOS, Boaventura de Sousa. Por uma concepção multicultural de direitos humanos. In: SOUSA SANTOS, Boaventura de (org). Reconhecer para libertar: os caminhos do cosmopolitismo cultural. Rio de Janeiro: Civilização Brasileira, 2003, p. 429-461.

SOUZA, Jessé. A gramática social da desigualdade brasileira. In A invisibilidade da desigualdade brasileira. Belo Horizonte: Editora UFMG, 2006.

VEZZULLA, Juan Carlos. Teoria e Prática da Mediação. Paraná: Instituto de Mediação e Arbitragem do Brasil, 1998.

VIANA, Márcio Túlio. O dia a dia do juiz e as discriminações que o acompanham. Revista do Tribunal Regional do Trabalho da $3^{a}$ Região, Belo Horizonte, MG, v. 30, n. 60, Jul./Dez. 1999, p. 177-179.

WARAT, Luís Alberto. Ecologia, psicanálise e mediação. Trad. de Julieta Rodrigues, Porto Alegre: Sérgio Antônio Fabris, 1995, citado por Marcelo Paes Menezes, A crise da Justiça e a mediação, Revista do Tribunal Regional do Trabalho da $3^{a}$ Região, Belo Horizonte, 33 (63): Jan./Jun. 2001, p. 23-31.

WOLKMER, Antonio Carlos. Mudanças de Paradigmas, Pluralismo e Novos Direitos. Revista Espaço Jurídico, Joaçaba: v. 7, n. 2, Jul./Dez. 2006, p. 87-95.

WOLKMER, Antônio Carlos. Pluralismo jurídico: fundamentos de uma nova cultura no Direito. 3. ed. São Paulo: Salfa Omega, 2001. 